\title{
TRES NUEVOS POEMAS MEDIEVALES
}

La sección de Diversos del Archivo Histórico Nacional de Madrid guarda documentos de gran interés, ignorados en su mayoría, debido a que esa sección se formó, desde sus orígenes, como por aluvión: todo lo que no encaja concretamente en alguna de las otras secciones va a parar a ésta, y así se ha ido acrecentando su pequeño núcleo primitivo por compras, donaciones o ingresos circunstanciales. Bucear en sus fondos es como abrir una caja de sorpresas. A ellos pertenece el documento que aquí damos a conocer.

Se trata de tres composiciones poéticas. La primera es un relato del pecado original; la segunda, intitulada $i A y$, Iherusalem!, es una lamentación por la pérdida de los Santos Lugares y una descripción de los horrores que acompañaron a esa pérdida; la tercera es una breve exposición de los Diez Mandamientos. El documento no tiene fecha ni firma. Del examen paleográfico y diplomático se deduce que se escribió hacia finales del siglo xIv o comienzos del xv. A los investigadores literarios dejamos la tarea de fijar la fecha de composición de las tres poesías y de apreciar su mérito.

¿Cómo ha llegado hasta aquí tan interesante escrito? El inventario original de entrada se ha perdido, y sólo se conserva una copia sin fecha, pero que, por el número de orden que llevan todos los papeles, hay que situar entre $190_{5}$ y $1917^{1}$. No tenemos más datos sobre su procedencia, ni más noticia que la indicación escrita en letra de principios de este siglo en la carpetilla que lo contiene, y que dice simplemente: "Tres poesías, en dos hojas de papel".

He aquí la transcripción de las poesías ${ }^{2}$ :

\section{I}

El Dio alto que los çielos sostiene

e avm el agua con el fuego aviene

${ }^{1}$ El inventario que lleva el número anterior está fechado el $1^{0}$ de abril de 1905, y el que lleva el número siguiente es de 24 de agosto de 1917.

${ }^{2}$ Respeto en esta transcripción todas las características del ms., y así mantengo, por ejemplo, la $u$ con valor de $v$ y viceversa. Sólo he desarrollado las abreviaturas y he modernizado la puntuación y añadido los acentos; también he corregido el uso arbitrario de mayúsculas y minúsculas. Sigo las normas paleográficas de García Villada (Paleografía española, Madrid, 1923) y Millares Carlo (Tratado de paleografía española, Madrid, 1932). 
e la tierra sobre el agua detiene,

gouernador que a los biuos mantiene,

el su nonbre en la ley lo a metido

para darlo al su pueblo escogido.

Bendixeran el su nonbre a vna los nasçidos e ninnos de la cuna, e dixeron: "Este relanpa e truna

10 e saca sol e estrellas e luna".

Quando el Dio Adán ovo criado, él se estaua durmiendo asosegado, e a la muger sacó del su costado para seruirlo e fazer su mandado.

Quando Adán en el huerto se estaua guardándolo, e bien se lo labraua, el culebro por la puerta entraua; a la muger al oýdo le fablaua.

Díxole asý: "Muger, vete ${ }^{3}$ comigo 20 a vn árbol donde ay tanto buen figo: comeremos e averme as por amigo, e saberás quál es el pan de trigo".

Desque de los figos se oviera fartado, al marido vn figo le avía dado: nunca Adam comió tan mal bocado.

Desque sus ojos ovieran abiertos, sus vergüenças de fuera se las vieron: con fojas $[\ldots]^{4}$ se las cubrieron e tras vn árbol con temor se ascondieron.

3o Luego el Dio del çielo dio vn grand grito: “¿Dónde estás, Adán? ¿Dónde te as ascondido? Sy del árbol del saber as comido, ipor el mi nonbre, caro será vendido!"

Dixo: “Ay, Sennor! ¡Por malo fue [sic] nasçido! La muger que me distes me ay vendido:

${ }^{3}$ El copista olvidó quizá en esta palabra el signo de abreviación de $n$.

4 Este verso resulta anómalamente corto. El original diría quizá "con fojas de figuera..." (cf. Génesis, 3:7, en las versiones escurialenses: Biblia medieval romanceada, ed. A. Castro, A. Millares Carlo y A. J. Battistessa, Buenos Aires, 1927 , p. 4 b; Biblias medievales romanceadas, ed. J. Llamas, Madrid, 195o, p. 17 ; Escorial Bible I.j.4, ed. O. H. Hauptmann, Philadelphia, 1953, p. 57). 
de su mano dado me avía vn figo, no sé sy era del árbol defendido".

Commo la muger se viera en fuerte presa, allý fabló con su lengua suelta:

40 " $\mathrm{Ayy}$, Sennor! $¡ E l$ culebro me ay muerta, pues tú me feziste de vna costilla tuerta!"

Luego el Dio mandó juntar sus cortes; al culebro maldíxole las sortes, e a la muger parir con dolor forte, e al onbre dio grand lazario [sic] de morte.

Por este mal todos paremos mientes. Por los figos que comimos por los dientes todos morremos: asý farán los biuientes.

Maldito fue el linnaje primero, que creyeron en ydolos de madero e descreyeron del Sennor verdadero.

\section{II}

\section{¡Ay Iherusalem!}

A los que adoran en la vera cruz, salud e graçia de la vera luz, que enbió syn arte el maestre d'Acre
a Iherusalem.

Bien querria más convusco plannir, llorar noches e días, gemir e non dormir, que contarvos prosas de nueuas llorosas de Iherusalem.

Creo que pecado me sería callar;

lloros e sospiros non me dan vagar de escreuir el planto

en el Conçilio santo

de Iherusalem.

De Iherusalem vos querría contar, del Sepulcro Santo que es allende el mar: moros lo cercaron e lo derribaron,

20 a Iherusalem

Estos moros perros a la casa santa siete años e medio la tienen çercada; non dubdan morir por la conquerir a Iherusalem. 
Fazen $^{5}$ ayuntamiento los de Babilonia con los africanos para los de Etiopia, para los $[\ldots]^{6}$ tártaros e miros

3o por Iherusalem.

Grandes afmcanças ponen con sus lanças

por yr a christianos commo a perdonanças.

Llena por ençuna

vençe morería

en Iherusalem.

Haunque los christianos non pueden sofrir, han pocas viandas e mucho ferir.

Non les viene acorro

del su Consistorio

$4^{\circ}$ en Iherusalem.

la todos acuerdan con el Patriarcha:

Para el Padre Santo escriuen vna carta

con letras de sangre,

que mueren de fanbre

en Iherusalem.

Raros muy amargos moros quantos son

tiénenlo çerrado al altar de Syón.

Non dubdan morir

por la conquerir

$5^{\circ}$ a Iherusalem.

Léese la carta en el Conçilio santo:

papa e cardenales fazían grand llanto,

ronpen sus vestidos,

dan grandes gemidos

por Iherusalem.

Mandan dar pregones por la christiandad,

alẹan sus pendones, llaman Trinidad.

"Valed, los christianos,

a vuestros hermanos

6o en Iherusalem!"

Non les da buen viaje la sagrada mar:

los vientos an contrarios, non les dexa andar.

Quando están en calma

esflaquéçeles el alma,

en Iherusalem.

Ora es venida, por nuestros pecados,

de tan negro día moros esforçados.

Llena por encima

vençe morería

$7^{\circ}$ en Iherusalem.

5 Transcribo por $F$ un grafismo raro, que no puede tener otro sentido.

${ }^{6}$ Es claro que falta algo en este verso, seguramente porque el copista no entendió alguna palabra en el original. 
Pocos son christianos, menos que ovejas.

Muchos son los moros, más que las estrellas.

Non dubdan morir

por la conquerir

a Iherusalem.

iQuánta grand batalla fuera en aquel día!

Con los caualleros es la clerezía,

por tomar pasión

por la defensión

8o de Iherusalem.

Reuenden christianos muy bien la su sangre:

por muerte de vno cient moros van delante.

De todo por ençima

vençe morería

en Iherusalem.

Sacerdotes e frayres en cadenas presos;

tienen a los abades en cepos de maderos.

Afán e amargura

hanlo por folgura

go en Iherusalem.

Bienen las donzellas que eran delicadas

en cadenas presas e muy atormentadas.

Afán e quebranto,

fazian grande llanto

en Iherusalem.

Veen los christianos a sus fijos asar, veen a sus mugeres biuas destetar;

vanse por los caminos [sic]

cortos pies e manos

100 en Iherusalem.

De las vestimentas fazían cubiertas;

del Sepulcro Santo fazían establo;

de las cruzes santas

fazían estacas

en Iherusalem.

Quien este canto non quiere oýr,

non tiene mientes de a Dios seruir

nin poner vn canto

en el Conçilio santo

de Iherusalem.

Remiénbrense vuestros entendimientos

que diez son, diez, los santos mandamientos.

El primero non farás Dios estranno;

el segundo non jures Dios en vano; 
el tercero es las fiestas çelebrar;

el quarto es padre e madre onrrar;

el quinto non farás omeçida?

e lo seseno non farás forniçio;

lo seteno non furtar nin robar;

10 lo otauo non quieras diffamar;

lo noueno non cobdiçiar la casa

del próximo / nin bienes que lo valas;

lo dezeno, nin la muger velada.

Sy tú éstos fazes, avrás vida folgada.

Deo gratias.

\section{Estudio paleográfico}

Las tres composiciones están escritas en dos folios de papel, tamaño $295 \times 220 \mathrm{~mm}$., en estado de conservación satisfactorio ${ }^{9}$. El tipo de letra es el llamado "redonda libraria", o sean caracteres góticos algo suavizados por influencia de la cursiva de los diplomas. Este proceso de contaminación de una letra por la otra se inicia entre la segunda mitad del siglo xiII y los primeros años del xıv, dando lugar en este último siglo a su forma totalmente caracterizada, o sea la letra "semi-gótica". A través de este lapso hay rasgos que se mantienen casi sin variantes, mientras otros van evolucionando hasta llegar a los primeros años del siglo $\mathrm{xv}$.

Entre los grafismos que conservan casi sin variante su forma gótica primitiva están los siguientes: 1) la $c$, cuyo trazo superior es recto; 2) las letras que llevan trazos redondos, como son $o, b, p, d$, que aparecen un poco como talladas a facetas, tendiendo a ensancharse con menoscabo de su altura y a fundirse con la letra contigua cuando es también de trazo redondo; 3) las minúsculas $i, m, n, u$, de trazos cortados en vez de tenerlos rectos y curvos; 4) la doble forma de la $r$, y el empleo de la $r$ cuadrada a continuación de una letra curva (cf., en nuestro ms., fol. $1 \mathrm{r}^{0}$, col. 1 , lín. 4 gouernador, y lín. 5 nonbre); 5) la $s$, larga al comienzo y centro de palabra y siempre corta y de doble curva al final.

T El sentido gramatical y la exigencia de la rima hacen pensar que esta palabra debiera ser más bien omeçidio u omeçillo.

${ }^{8}$ En el ms., este verso comienza en la palabra nin. Corrijo la distribución del pareado, en razón del metro y de la rima.

"Sólo tienen los bordes rozados, y dos pequeñas perforaciones de carcoma que, afortunadamente, no impiden la lectura: una de ellas en la parte inferior izquierda del fol. 1, que cala al fol. 2, y la otra en la parte superior izquierda del fol. 2, que ha hecho desaparecer las letras -rdo- de la palabra Sacerdotes. 
Entre los grafismos que evolucionan en este período, mencionamos en particular: 1) la $d$, que en un principio era recta y que durante el siglo XIII va curvando su rasgo superior hacia la izquierda; a mitad de su evolución sólo es recta delante de $i$, y a fines del xIV se ha perdido por completo esta forma, en cuyo caso se encuentra nuestro ms.; 2) la $f$, que a mediados del siglo xiv, por influencia de la cursiva, comienza a hacerse larga y a veces doble; en nuestro documento aparece alargada pero sin duplicar (salvo una sola vez: fol. 2, col. 2, lín. 10 diffamar); 3) la $s$, que sufre ese mismo proceso; aquí la encontramos a veces extremadamente alargada, pero nunca doble (fol. $1 \mathrm{r}^{0}$, col. 1, lín. 1 sostiene, lín 19 asy; col. 2, lín. 1 sennor, lín. 5 presa); 4) la $v$, que con valor de $u$ en principio de palabra no se usa sino excepcionalmente en el siglo xirr, mientras que en nuestro ms. encontramos siempre vn, vna, vno; 5) la $y$, que con valor de consonante no se usa en el siglo xirr tan a menudo como en los siglos siguientes; aquí se le da el uso adecuado (fol. $1 \mathrm{r}^{\mathrm{o}}$, col. 2, lín. 17 y 18 creyeron y descreyeron; fol. $1 \mathrm{v}^{\circ}$, col. 1 , lín. 16 ayuntamiento; la única excepción es el $\mathrm{Ia}$, con mayúscula, del fol. $1 \mathrm{~V}^{\circ}$, col. 1 , lín. $31)$; 6) la $z$, que en el siglo xiv se ha convertido en una $s$ de doble curva con un trazo tangente arriba, de lo cual hallamos aquí abundantes Inuestras (fol. $1 \mathrm{r}^{\circ}$, col. 1, lín. 14 fazer, y col. 2, lín. 8 feziste), aunque a veces aparezcan formas un tanto anteriores.

También nos sirven para fechar el documento el modo de trazar las mayúsculas y el empleo y grafismo de las abreviaturas. En cuanto a las primeras hremos de decir que, si bien es común a los siglos XIII y xrv una gran libertad en su trazo - utilizándose indistintamente unciales, capitales, o minúsculas agrandadas en cuyo interior aparecen como muy características dos (o cuatro) rayitas paralelas-, esta anarquía va aumentando al correr de los años. Nuestro ms. está ya en una fase bastante avanzada. Sirva de ejemplo la $D$, cuyo grafismo aparece diferente casi tantas veces como se emplea (cf. fol. $1 \mathrm{r}^{\circ}$, col. 1 , lín. 19 Dixo, lín. 23 Desque, lín. 26 Desque; col. 2, lín. 1 Dixo; fol. $1 \mathrm{v}^{\circ}$, col. 1, lín. $6 \mathrm{De}$; fol. 2, col. 1, lín. $21 \mathrm{De}$ ). Lo mismo cabe decir de las demás mayúsculas.

También es propia de los siglos xiv a xv la gran libertad que reina en cuanto a las abreviaturas. La de $m$ y $n$, que en el siglo XIII se reducía a un grueso punto, en nuestro documento adopta formas diversas que le colocan en época un tanto avanzada. Unas veces es la simple raya, otras el signo de omega, otras un rasgo arbitrario en que la omega aparece deformada o añadida (fol. $1 \mathrm{r}^{\circ}$, col. 2, lín. 13 mientes, y lín. 16 linnaje); alguna vez se utilizan dos signos superpuestos para una sola $m$ eludida (fol. $1 \mathrm{r}^{\circ}$, col. 2, lín. 5 commo), o bien se une su rasgo al de una abreviatura del verso anterior, adoptando la forma de una $s$ de doble curva (fol. $1 \mathrm{r}^{0}$, col. 1, lín. 26-27), semejante al trazo que cierra la composición primera. La $s$ y la $r$ finales se 
sustituyen por un signo cuyo trazo varía notablemente de tamaño (cf. fol. I v $\mathrm{v}^{\mathrm{o}}$, col. I, lín. 26 sofrir, y fol. 2, col. I, lín. 11 delicadas). Hallamos en nuestro ms. la $i$ sobrepuesta de la sílaba pri, propia del siglo XIV (fol. I $\mathrm{r}^{\circ}$, col. 2 , lín. 16 y fol. 2, col. 2, lín. 3 primero). En cambio, para la abreviatura de $r e$ el copista superpone unas veces la $e$ (fol. $1 \mathrm{v}^{0}$, col. 2 , lín. 27 estrellas) y otras utiliza el mismo signo que emplea para la supresión de $-s$ y $-r$, como si se tratara de una $r$ no intermedia sino final (fol. $1 \mathrm{r}^{\circ}$, col. 2, lín. 5 presa). Es muy curioso cómo resuelve la abreviatura de por cuando tiene que utilizar $P$ mayúscula (fol. $1 \mathrm{r}^{\circ}$, col. 2, lín. 19). La supresión de $u a$, ie, común a los siglos XIII y xIV, figura en nuestro ms. con un signo muy semejante al utilizado en el ms. de Berceo del siglo xiv que se conserva en la Academia de la Historia (fol. $1 \mathrm{r}^{\circ}$, col. 1 , lín. 3 tierra, lín. 11 y 15 quando, lín. 22 qual). Del mismo modo se practica aquí (fol. 1 $\mathrm{r}^{\circ}$, col. 2 , lín. 17 y 20) la supresión de $u e$ en la palabra que, propia del siglo xIv; pero esta abreviatura no se hace siempre (cf. fol. $1 \mathrm{r}^{\circ}$, col. 1, lín. 1 y 4 ).

La conjunción $e$, que en el siglo xiII tiene un grafismo muy parecido al de la $r$ cuadrada, aparece aquí con la forma propia de fines del xIv y comienzos del xv, mostrando una sola vez el signo general de abreviación que se hace de uso corriente en esta última centuria por influencia de la cursiva (fol. $1 \mathrm{r}^{\circ}$, col. 2 , lín. 18 ).

\section{Estudio diplomático}

Así, pues, el examen paleográfico del documento lo sitúa entre los últimos años del siglo xIv y los primeros del xv. El examen diplomático nos confirma en esta fecha. Los dos folios, de papel un poco algodonoso, presentan un ligerísimo rayado a lápiz, casi imperceptible a veces, por cuyas pautas se ha guiado el copista para mantener en línea el comienzo de las estrofas así como la separación de ambas columnas y comienzo y final de las mismas. Esa costumbre se inicia a finales del siglo $\mathrm{xI}^{10}$. El color rojizo de la escritura delata el empleo de la tinta compuesta por sulfato de hierro, nuez de agallas, goma y agua, que comienza a usarse en el siglo XIII y se generaliza en los dos siglos siguientes. Pero lo que nos es particularmente útil para fechar el documento es el examen del papel por tacto y transparencia. Su calidad algodonosa pero ya algo satinada encaja perfectamente en los finales del siglo xiv y comienzos del xv. Pueden apreciarse a trasluz las líneas de puntizones, con vírgulas cosidas, que dan lugar a doce espacios (entre los dos folios), todo lo cual es propio de esta época. Hacia el centro del primer folio hay una filigrana en forma de cruz latina de fantasía, semejante a un árbol de tres brazos rematados en flor de lis. El hecho de estar centrada la

10 E. Sarrablo Aguareles, Nociones de diplomática..., Alcalá, 1941. 


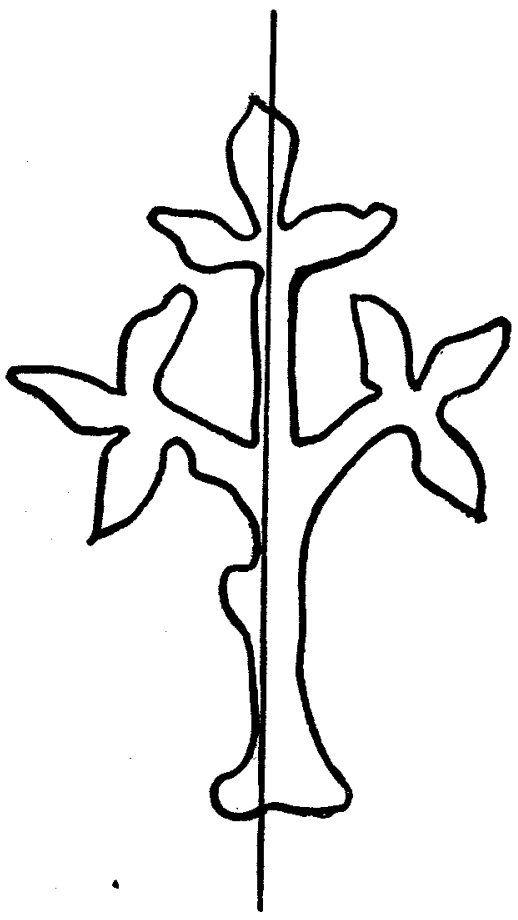

Filigrana, Grenoble, 1357 (Hommages rendus aux Dauphins).

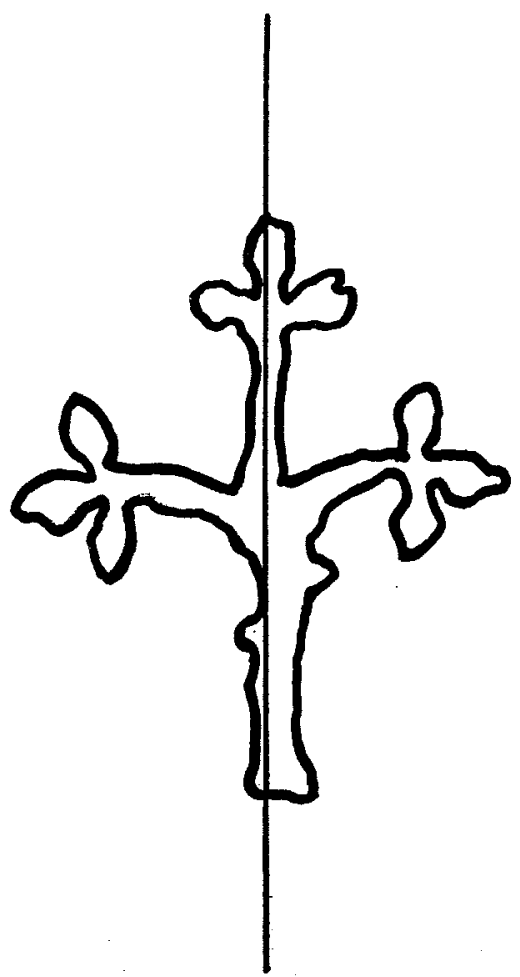

Filigrana del documento que presentamos.

filigrana, y el de aparecer ésta sobre un eje de puntizones suplementarios, nos dan como terminus a quo para la fabricación del papel el último cuarto del siglo xIv, pues con anterioridad a estos años la filigrana estaba a un lado y carecía de eje suplementario' ${ }^{11}$.

María del Carmen Pescador del Hoyo

Archivo Histórico Nacional Madrid.

11 G. M. Briquer, Les filigranes, Leipzig, 1923, t. 2, p. 331, ofrece un ejemplo de vírgulas cosidas de Treviso, 1382, y de filigrana sobre puntizones suplementarios, en papel también italiano, del año 139o. Según Briquet, la cruz latina de fantasía en forma de árbol dura unos cincuenta años (cita ejemplos de papeles fechados en Montpellier, 1969, en Grenoble, 1957, y otros más). 